\section{Mats Thulin - The Genus Boswellia (Burseraceae). The Frankincense Trees}

Symbolae Botanicae Upsalienses 39: 1-149 (2020).

Uppsala Universitet

ISSN 0082-0644

ISBN 978-91-513-0886-9

http://urn.kb.se/resolve?urn=urn:nbn:se:uu:diva- 405908

Price: 279 SEK

Among the contributions on the Flora of Horn of Africa this book on the Frankincense Trees here reviewed represents an excellent example of taxonomic research carried out over a period of decades by Prof. Thulin, recently retired from the University of Uppsala, but still active.

Let me come back to few decades ago in 1999, when I visited the Soqotra Archipelago (Yemen), a 40-day expedition together with the former curator of the Tropical Herbarium (FT) of Florence, Marcello Tardelli. In addition to the beauty of the landscape and the friendliness of inhabitants, what fascinated me was the incredible biological diversity of the Archipelago, and its high rate of endemism. Among the most interesting genera, such as Croton, Dendrosycios, Dracaena, Euphorbia, Hypericum, and many others, Boswellia had a special impact not only due to its naturalistic and taxonomic value, but also for its cultural meaning, considering the historical-religious and symbolic role of frankincense tree in ancient cultures from the Egyptians to the present day. As soon as I knew about this contribution on the genus Boswellia, it awakened an extreme interest in me, considering the experience and competence of the writer.

The author reminds to have met the Frankincense Trees for the first time in September 1975 during a collecting trip to Ethiopia, and subsequently to Kenya. The turning point was on the occasion of the SomaliSwedish project on the production of incense in Somalia that permitted the study of natural populations in crucial areas such as Somaliland, and southern Arabia. Of crucial importance were the nineties, during which Mats Thulin carried out a careful study of Boswellia in



the Soqotra Archipelago and southern Arabia, thus covering the entire distribution area in the African-Arabic area. So we can deduce that this work is part of 45 years of taxonomic research in the Horn of Africa and Arabic peninsula, a period that also saw the publication in four volumes of the Flora of Somalia, written and edited by the same author.

The book begins with a historical retrospective on the meaning of incense from the Egyptians to recent times, through the Greeks, Romans, and the Middle Ages, having represented a commercial product of high practical and symbolic value, especially in the Chris- 


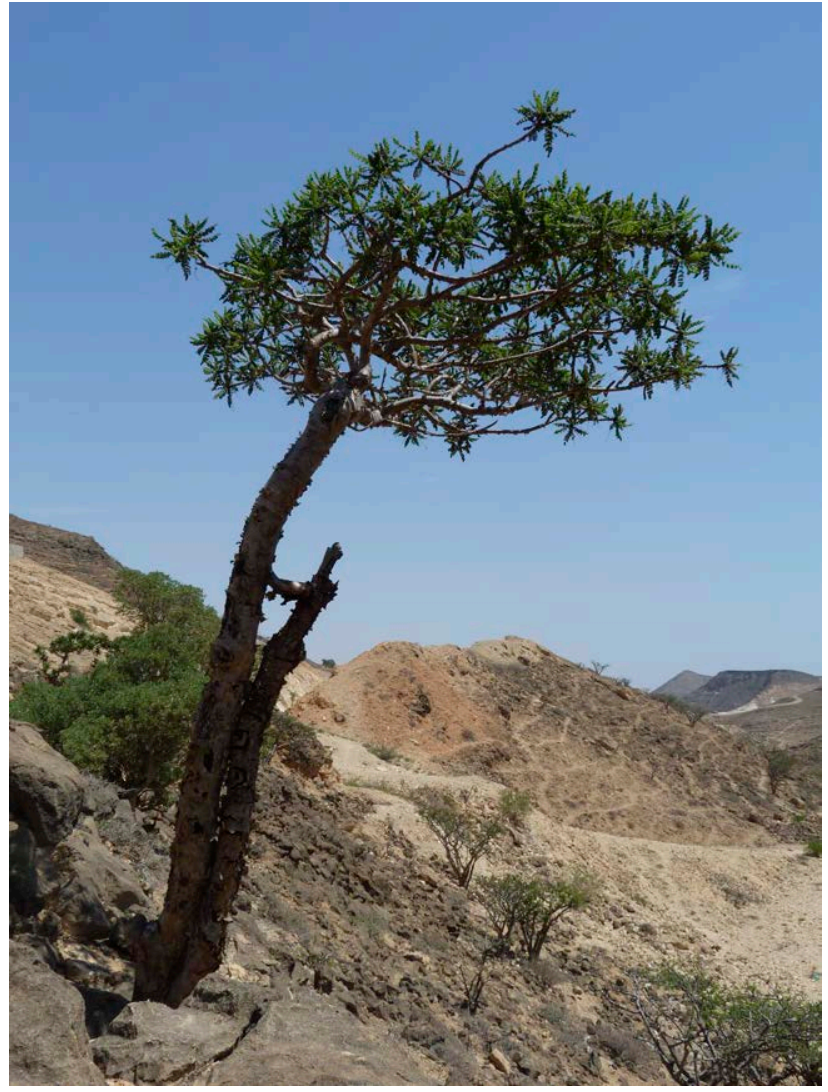

Boswellia sacra Flück. (Sultanate of Oman, Dhofar, wadi area near Mughsayl (photo: 2015, Lia Pignotti).

tian, Islamic liturgies and in the Ethiopian Orthodox Church. The Royal Danish Expedition to Egypt and Yemen (Arabia Felix) between 1761 and 1763 is also remembered. This expedition had the aim of investigating the origin of the various products mentioned in the Bible, including incense. A taxonomic description of the genus Boswellia follows, focusing on the major contributors of the past, such as Balfour, Guillaumin, Hutchinson, Chiovenda, Engler, Capuron, Hepper.

Particular importance is placed on the phylogeny of the genus Boswellia, recently studied and supported as monophyletic with the exception of the genus Ambilobea of Madagascar, focusing on three areas of differentiation: an Indian clade, an African clade, and a Soqotran clade, the latter represented by the largest number of species (seven). In the phylogenetic and phylogeographical scenario of the genus Boswellia, the archipelago of Soqotra is definitely the most interesting area of its evolutionary radiation.

The introduction to the genus Boswellia begins with a detailed description, followed by information on the following aspects: geographical distribution, morpho- anatomical characters, growth, reproductive biology and pollination, dispersion, cytology, hybridization, conservation, uses, and incense harvesting and processing.

The chapters dedicated to each species are preceded by a general identification key.

Type information of accepted names and synonyms is included, in many cases with comments on nomenclature. New lectotypes are also designated. Distribution, vernacular names and uses, IUCN Red List assessment, and taxonomic remarks are reported.

Herbarium specimens are grouped by geographical area and transcribed in detail. In many cases, line drawings are provided. The original photo documentation of the author and his close collaborators is also fundamental for understanding the environment where the species described in the text live.

A total of 24 Boswellia species are presented, including 2 new species: Boswellia samhaensis Thulin \& Scholte (Samha island, Soqotran Archipelago), Boswellia scopulorum Thulin (Soqotra). A "new" species still under study, Boswellia "hesperia" sp. prov. from Soqotra is proposed as related to Boswellia popoviana Hepper, also from Soqotra Island. Last but not least a new combination is proposed: Boswellia aspleniifolia (Balf. F.) Thulin., comb. nov.

"Species excludendae" amounts to 7, all referable to genera different from Boswellia such as Canarium, Dysoxylum, Garuga. Particular critical attention is paid to Boswellia bricchettii (Chiov.) Chiov. An updated and useful bibliography for future investigations on Boswellia is listed at the end of the book.

This work by Mats Thulin represents a turning point in the knowledge of one of the most interesting paleotropical genera extending from Mali and Burkina Faso to west India, through the Ethiopian / Arabic area.

What makes us proud of this contribution is the recognition it gives to the University of Florence with the Tropical Herbarium FT, which has received the author for many years as a frequent and precious visitor.

This, this book - distinguished by the rigor with which it was conceived and then realized after years of study - is an example of how a monograph should be written: a clear message in a current editorial scenario in which, many times, improvisation and science publication frenzy led to poor results in Plant Taxonomy.

\author{
Riccardo M. Baldini \\ Editor in Chief of Webbia \\ Department of Biology and \\ "Centro Studi Erbario Tropicale" \\ (Tropical herbarium FT) \\ University of Florence, Italy
}

